\title{
The efficacy of combined Albendazole and Praziquantel therapy versus Albendazole monotherapy in treatment of parenchymal neurocysticercosis: A systematic review
}

\section{Gaurav Nepal ${ }^{1}$, Jessica Holly Rehrig ${ }^{2}$, Rajan Sharma Kandel ${ }^{1}$, Shaik Tanveer Ahamad ${ }^{3}$, Bipin Kandel ${ }^{1}$, Rajeev Ojha ${ }^{1}$, Jayant Kumar Yadav ${ }^{1}$, Sujan Jamarkattel ${ }^{4}$, Ravi Shah ${ }^{1}$, Jeevan Gautam ${ }^{1}$, Gentle Sunder Shrestha ${ }^{1}$}

${ }^{1}$ Maharajgunj Medical Campus, Tribhuvan University Teaching Hospital, Maharajgunj, Kathmandu, Nepal; ${ }^{2}$ Department of Neurology, North Shore University Hospital, NY, United States;

${ }^{3}$ Deccan College of Medical Sciences, Hyderabad, India;

${ }^{4}$ Tufts Medical Centre, Boston, MA, United States.

Keywords: Albendazole, neurocysticercosis, praziquantel



This work is licensed under a Creative Commons Attribution 4.0 Unported License.

\begin{abstract}
Preliminary studies suggest combined albendazole and praziquantel $(\mathrm{ABZ}+\mathrm{PZQ})$ therapy has superior anti-parasitic effect compared to albendazole (ABZ) or praziquantel (PZQ) monotherapy, due to potential pharmacokinetic synergism. We thus present an evidence-based review evaluating the risks and benefits associated with combination $\mathrm{ABZ}+\mathrm{PZQ}$ therapy compared to standard ABZ monotherapy in the treatment of viable parenchymal Neurocysticercosis (NCC). Our systematic review is based on PRISMA (Preferred Reporting Items for Systematic review and MetaAnalysis) statement. Our primary outcome measure was to compare the efficacy of $\mathrm{ABZ}+\mathrm{PZQ}$ with $\mathrm{ABZ}$ alone for treatment of NCC. Efficacy was determined based on clinical and radiographic evaluation. The secondary outcome measured the incidence of adverse effects in each treatment group. Literature search yielded a total of 120 articles. After excluding duplicates and those not meeting inclusion criteria, five papers were reviewed for data collection. Medication regimens, number of cyst, patient age, and location varied amongst included papers. The combination therapy resulted in significant symptom and cyst resolution in patients with more than two viable parenchymal cysts as compared to monotherapy. The two treatment arms were comparable in treating NCC with low cyst burden. There was no significant difference in the adverse effects between two treatment groups. In individuals with multi-cystic NCC, the patients who received dual therapy had better outcomes than those who received ABZ monotherapy as evidenced by radiographic improvement and reduced seizure episodes. The adverse effect profile in patients receiving dual therapy was similar and comparable to those with monotherapy.
\end{abstract}

\section{Introduction}

The World Health Organization (WHO) estimates that about 2.56-8.30 million individuals worldwide are suffering from neurocysticercosis (NCC), making it the most common parasitic disease of the central nervous system (CNS). ${ }^{1}$ The Center of Disease Control (CDC) has classified NCC as one of the five neglected parasitic infections (NPIs) due to the minimal attention this widely prevalent condition has received from public, clinical, and research communities. ${ }^{2}$ NCC occurs due to the ingestion of the eggs of the parasite Taenia solium, which

\section{*Corresponding Author:}

Dr. Gentle S Shrestha, MD, FACC, EDIC, FCCP, FNCS

Associate Professor

Department of Anaesthesiology

Tribhuvan University Teaching Hospital

Maharajgunj, Kathmandu, Nepal

Tel No. 977-9841248584

Email: gentlesunder@hotmail.com 
The efficacy of combined Albendazole and Praziquantel therapy versus Albendazole monotherapy in treatment of parenchymal neurocysticercosis: A systematic review

is capable of cysticerci formation in various human organs. It is the leading global cause of preventable epilepsy and accounts for $30 \%$ of all cases in Latin America, Asia, and Africa.

The cysticerci pass through three stages within the central nervous system: viable (vesicular), non-viable (colloidal and granular), and calcified. When a cyst transitions from viable to non-viable form, an associated inflammatory response is identified in the surrounding cortex, leading to clinical manifestations such as headache, nausea, vomiting, dizziness, stroke, psychiatric symptoms, and severe intracranial hypertension. ${ }^{3-5}$ After a cyst dies, the dystrophic calcified area acts as a focal point for seizure activity. If left untreated, it may lead to complications such as epilepsy, hydrocephalus, cerebral herniation and death. ${ }^{4}$ The MRI features of parenchymal neurocysticercosis is given in Figure 1.

Therapy is largely anchored in antiparasitic agents, most commonly albendazole (ABZ) or praziquantel (PZQ). ${ }^{1,5}$ ABZ acts by binding to the colchicine-sensitive portion of tubulin, inhibiting assembly of cytoplasmic microtubules necessary for glucose uptake in larval and adult forms of the parasite. PZQ disrupts calcium ion homeostasis in the worm and the current consensus is that it antagonizes voltage-gated calcium channels. It is hypothesized that disruption of these channels results in uncontrolled calcium ion influx leading to uncontrolled muscle contraction and paralysis. ${ }^{6}$ In addition to the antiparasitic therapy, corticosteroids and anti-epileptics are used to mitigate perilesional edema and treat seizures respectively. ${ }^{1,5}$

Guidelines around the world support the use of $\mathrm{ABZ}$ for active NCC. However, recently, combination therapy with PZQ has generated significant interest among clinicians. Combined albendazole and praziquantel $(\mathrm{ABZ}+\mathrm{PZQ})$ therapy has shown to have potential pharmacokinetic synergism by increasing plasma concentrations of albendazole sulfoxide, ${ }^{7}$ albendazole sulfone, albendazole sulphoxide and PZQ metabolites. ${ }^{8}$ Apart from $\mathrm{NCC}$, the $\mathrm{ABZ}+\mathrm{PZQ}$ combination has been used successfully in the treatment of other parasitic conditions, including hydatid disease $^{9-11}$ and schistosomiasis. ${ }^{12}$

To date, only a few studies have been published directly comparing $\mathrm{ABZ}+\mathrm{PZQ}$ dual therapy to $\mathrm{ABZ}$ monotherapy in the treatment of viable parenchymal NCC. Extrapolation of existing data is limited by the small sample size of the studies. ${ }^{6,13-16} \mathrm{We}$ aim to present a substantial evidence-based review of the studies evaluating the risks and benefits associated with combined $\mathrm{ABZ}+\mathrm{PZQ}$ therapy compared to $\mathrm{ABZ}$ monotherapy in viable parenchymal NCC.

\section{Methods}

Our systematic review utilized the PRISMA(Preferred Reporting Items for Systematic review and Meta-Analysis) statement in conjunction with the PRISMA checklist and flow diagram for manuscript format development. ${ }^{17}$

\section{Literature search}

The following databases served as sources for published studies prior to June 2019: PubMed, Google Scholar and China National Knowledge Infrastructure (CNKI). Searches were conducted using the keywords "combined albendazole and praziquantel", "albendazole and praziquantel”, and "albendazole plus praziquantel" in combination with "neurocysticercosis" or "NCC". Titles, abstracts, and full text were screened for the study and report characteristics that matched eligibility criteria. Two authors (RSK and GN) screened, retrieved, and excluded reports. An additional investigator (JR) participated in the review process when eligibility uncertainty arose.

\section{Eligibility criteria}

The study must be carried out on human subjects, distinctly state the study design, sample size, inclusion criteria, baseline characteristics of the patients, and drug dosage administered. It should compare $\mathrm{ABZ}+\mathrm{PZQ}$ with $\mathrm{ABZ}$ alone in patients with viable parenchymal NCC and have reported clinical and/ or radiological outcomes following therapy. Studies across all languages were included.

\section{Data extraction}

Data was manually extracted from the eligible studies by the research investigators. The following variables were included: first author, type of design, site of study, year of publication, sample size, doses of drugs, concomitant therapy, mean age of participants, male to female ratio of participants, baseline number of cysts identified on imaging, follow-up, outcomes and adverse effects of medications.

\section{Outcome measures}

Our primary outcome measure was to compare the efficacy of $A B Z+P Z Q$ with $A B Z$ alone for treatment of NCC. Efficacy was based upon clinical and radiographic improvement. The secondary outcome measured the incidence of adverse effects in each treatment group.

\section{Results}

In total, our literature search yielded 120 articles. After excluding duplicates and those not meeting inclusion criteria, five papers were reviewed for data collection. Figure 2 displays the results of our literature search and selection. The characteristics of each study are summarized in Table 1 and Table 2.

\section{Study characteristics:}

Two of the five studies were non-randomized trials ${ }^{13,14}$ and the remaining three utilized a randomized, double-blinded, placebocontrolled methodology. ${ }^{6,15,16}$ Date of publications ranged through 2001-2016, and were conducted in India, ${ }^{6}$ China, ${ }^{13,14}$ and Peru ${ }^{15,16}$ respectively. In all included studies, ABZ+PZQ combined therapy was compared with $\mathrm{ABZ}$ monotherapy. Xu et al. had 40 subjects in the $\mathrm{ABZ}+\mathrm{PZQ}$ and 631 in $\mathrm{ABZ}$ group. ${ }^{14}$ Guo et al. had 30 subjects in each group, ${ }^{13}$ while Kaur et al. had 53 subjects in the $\mathrm{ABZ}+\mathrm{PZQ}$ and 50 in the $\mathrm{ABZ}$ arm. ${ }^{6}$ In 2014, Garcia et al. conducted a phase 3 study with $39 \mathrm{ABZ}+\mathrm{PZQ}$ and $41 \mathrm{ABZ}$ subjects. ${ }^{16}$ In 2016, Garcia et al. published their phase 2 trial data with 16 subjects in each group. ${ }^{16}$ Baseline patient characteristics are tabulated in Table 2. There was some variability in age in the study population. Xu et al, ${ }^{14}$ and Guo et al., ${ }^{13}$ both the trials from China, had set no age limitation for inclusion in their studies. Kaur et al. focused on pediatric patients, ${ }^{6}$ while Garcia et al. $(2014)^{15}$ and Garcia et al. $(2016)^{16}$ included adult patients only.

\section{Drugs and Doses:}

\section{Combined Albendazole-praziquantel:}

Combined therapeutic regimens varied in dosage and frequency across the reviewed studies. Xu et al. administered ABZ 20 $\mathrm{mg} / \mathrm{kg} /$ day for 12 days, followed by PZQ $30 \mathrm{mg} / \mathrm{kg} / \mathrm{day}$ for 12 days as a course, with two courses in total given with a two to three-month intermission period in between. ${ }^{14}$ Guo et al. used a cumulative dose of $100 \mathrm{mg} / \mathrm{kg}$ for $\mathrm{ABZ}$ and $\mathrm{PZQ}$, respectively, over two to four weeks. ${ }^{13}$ Kaur et al. administered ABZ $15 \mathrm{mg} /$ $\mathrm{kg} /$ day for seven days and PZQ $75 \mathrm{mg} / \mathrm{kg} /$ day for one day. ${ }^{6}$ Garcia et al. (2014) and Garcia et al. (2016) followed a 10-day regimen of $\mathrm{ABZ}(15 \mathrm{mg} / \mathrm{kg}$ per day) combined with PZQ (50 $\mathrm{mg} / \mathrm{kg} /$ day).$^{15,16}$ 


\section{Albendazole alone:}

Medication dosage and frequency was variable in the control arm as well. Xu et al. started a course of ABZ at $15 \mathrm{mg} / \mathrm{kg} / \mathrm{day}$ for 15 days and repeated the course after a two to three-month intermission period. ${ }^{14}$ Guo et al. followed a total dose of ABZ 200 $\mathrm{mg} / \mathrm{kg}$ given over two to four weeks.13 Kaur et al. administered $\mathrm{ABZ}$ at $15 \mathrm{mg} / \mathrm{kg} /$ day for seven days. ${ }^{6}$ Garcia et al. (2014) and Garcia et al. (2016) used ABZ $15 \mathrm{mg} / \mathrm{kg} /$ day for ten days. ${ }^{15,16}$

\section{Concomitant therapy:}

$\mathrm{Xu}$ et al. did not mention concomitant therapy used during antiparasitic treatment of neurocysticercosis. ${ }^{14}$ Guo et al. utilized neuroprotective agents, anti-epileptics and drugs to reduce the raised intracranial pressure, as necessary. ${ }^{13}$ Kaur et al. managed patients with oral prednisolone $(2 \mathrm{mg} / \mathrm{kg} /$ day $)$, for the first five days of treatment, and carbamazepine dosed at 12 to $15 \mathrm{mg} /$ $\mathrm{kg} /$ day. ${ }^{6}$ Garcia et al. (2014) and Garcia et al. (2016) used the following as concomitant therapy: an anti-epileptic (phenytoin or carbamazepine), dexamethasone $0.1 \mathrm{mg} / \mathrm{kg} /$ day in divided doses (morning and evening), and $300 \mathrm{mg} /$ day of ranitidine. ${ }^{15,16}$

\section{End-point assessment:}

$\mathrm{Xu}$ et al. expressed the results in the form of a short-term effective rate, which was calculated using the criteria set by Ma Yunxiang et al. ${ }^{18}$ The rate was based on clinical evaluation and CT/MRI results following one year of therapy. ${ }^{14}$ Guo et al. documented pre-therapy predominant symptoms such as headache and seizure and MRI findings and compared them following therapy, as an indicator for treatment efficacy. A symptom-score difference of $\geq 1$ and an MRI indicating the resolution of $\geq 75 \%$ of lesions was assumed to be effective based on the criteria. ${ }^{13}$ Kaur et al. compared the treatment group CT imaging characteristics at the 1,3 , and 6 month follow ups and seizure recurrence rates at 1 -year. ${ }^{6}$ Garcia et al. (2014) primarily reviewed differences in complete MRI cyst resolution at 6 months. Other outcomes were the proportions of resolved cysts between study groups, the effect of complete cyst resolution on seizure frequency, and the number of cysts remaining after antiparasitic treatment. ${ }^{15}$ Garcia et al. (2016) only looked for cysticidal efficacy (i.e. the proportion of cysts resolved) using a baseline and follow-up MRI after six months of treatment. ${ }^{16}$

\section{Efficacy of the therapy:}

$\mathrm{Xu}$ et al.'s short-term effective rates after one year of therapy was $55.0 \%$ for $\mathrm{ABZ}$ and $98.1 \%$ for $\mathrm{ABZ}+\mathrm{PZQ}(\mathrm{p}<0.01) .{ }^{14} \mathrm{Guo}$ et al. concluded that $46.7 \%$ in the $\mathrm{ABZ}$ arm reported to have improvement in both clinical and radiological manifestations, compared to $80.8 \%$ in the $A B Z+P Z Q$ arm $(p=0.03)$. Seizures were controlled in $43.3 \%$ of ABZ group compared to a higher percentage of control at $76.7 \%$ in the ABZ+PZQ group $(\mathrm{p}=0.027)$. MRI lesion improvement was seen in $50 \%$ patients in the former group and $86.7 \%$ in the latter $(\mathrm{p}=0.006) .{ }^{13}$

Kaur et al. included only NCC cases with single cystic lesions in their study. Complete resolution of CT brain lesions at one, three, and six months was higher in $\mathrm{ABZ}+\mathrm{PZQ}$ dual therapy $(35 \%, 60 \%$, and $72 \%$ respectively) versus $\mathrm{ABZ}$ monotherapy (25\%, 42\%, and $52.0 \%$ respectively) with no statistical significance $(\mathrm{p}>0.05)$. Delayed or non-resolution of lesions and calcification of lesions respectively was lower in the $A B Z+P Z Q$ group compared to $A B Z$ patients at follow-up, but this was not statistically significant ( $\mathrm{p}$ $>0.05){ }^{6}$

In the 2014 study by Garcia et al., the proportion of patients with complete cyst resolution in MRI at 6 months was significantly higher at $64 \%$ in the $\mathrm{ABZ}+\mathrm{PZQ}$ combination group compared to $37 \%$ in the standard $A B Z$ group $(\mathrm{p}=0.014)$. The proportion of patients with complete cyst resolution was similar between treatment arms for patients with one and two cysts. However, for patients with three or more cysts, complete cyst resolution was significantly higher in the combination group compared with those in the standard ABZ group $(\mathrm{p}=0.007)$ or increased $A B Z$ group $(\mathrm{p}=0.016) . A B Z+P Z Q$ dual therapy resolved more cysts than did standard ABZ $(\mathrm{P}<0.0001)$ or increased ABZ $(\mathrm{p}=0.0005)$. No significant difference existed $(\mathrm{p}=0.792)$ in seizure frequency during days 1-60 of treatment with dual therapy (46\%) versus standard albendazole (39\%) versus high-dose albendazole (45\%) or during days $61-180(\mathrm{p}=0.624)$ with seizure frequency seen at $26 \%, 17 \%$ and $24 \%$ respectively for the aforementioned regimes. ${ }^{15}$

The 2016 study by Garcia et al. found that cysticidal efficacy was higher in the $\mathrm{ABZ}+\mathrm{PZQ}$ group (95\%) than in the $\mathrm{ABZ}$ group $(30 \%)(\mathrm{p}<0.001)$. The cysticidal efficacy of $A B Z+P Z Q$ therapy was significantly increased in patients with three or more cysts than in those with one or two cysts $(\mathrm{p}<0.001)$. Similarly, the proportion of patients with complete cyst clearance was higher in the $\mathrm{ABZ}+\mathrm{PZQ}$ group (75\% compared to those in the $\mathrm{ABZ}$ group $(25 \%){ }^{16}$

\section{Adverse Effects of the therapy:}

$\mathrm{Xu}$ et al. reported the following adverse effects of antiparasitic therapy: fever, headache and dizziness, seizure, raised transaminase, transient unconsciousness, fundus edema/ hemorrhage, limb numbness and urticaria. The incidence of adverse effects in the $\mathrm{ABZ}+\mathrm{PZQ}$ group was high compared to $\mathrm{ABZ}$ group, and as the course of treatment progressed, adverse reactions gradually reduced.14 Guo et al. found that no significant adverse reactions occurred in either group. However, they measured the intracranial pressure of their patients which was found to be higher in the $\mathrm{ABZ}+\mathrm{PZQ}$ group $(2.02 \pm 0.43) \mathrm{kPa}$ in comparison to the $\mathrm{ABZ}$ group $(1.83 \pm 0.54) \mathrm{kPa}$, although the findings were not significant $(\mathrm{p}=0.27){ }^{13}$

Kaur et al. found that both ABZ and PZQ were well tolerated in the study population. There were no reports of epigastric discomfort or other gastrointestinal sequelae. Three children in the $\mathrm{ABZ}+\mathrm{PZQ}$ group and two in $\mathrm{ABZ}$ group developed headache on day 3 to 4 of treatment, which lasted for 1 to 2 days. Signs of raised intracranial pressure were not recorded in any patient during or after therapy. No participants in the study required withdrawal of medication as a result of adverse effects. ${ }^{6}$

In the study carried out by Garcia et al. (2014), no significant differences in severe adverse effects existed between groups. Headache was noted in three (7\%) patients on $\mathrm{ABZ}+\mathrm{PZQ}$ group and two (5\%) receiving ABZ. Drug-induced hepatitis occurred in one $(2 \%)$ patient assigned to the ABZ group. 15 Garcia et al. (2016) found no serious side effects within the entire study population. They accessed the hematologic and biochemical profiles of all participants and found no statistical difference between the patients receiving $\mathrm{ABZ}+\mathrm{PZQ}$ and those receiving $\mathrm{ABZ} \cdot{ }^{16}$

\section{Discussion}

In this systematic review, we compared the efficacy and safety of combined $A B Z+P Z Q$ therapy versus $A B Z$ alone in viable parenchymal NCC, and found the former is more efficacious than the latter in achieving symptom and radiographic lesion resolution in multi-cystic NCC. There was no significant difference between dual and monotherapy side effect profiles.

All but Kaur et.al. found that dual therapy significantly increased the likelihood of symptom and radiographic lesion resolution 
The efficacy of combined Albendazole and Praziquantel therapy versus Albendazole monotherapy in treatment of parenchymal neurocysticercosis: A systematic review

compared to $\mathrm{ABZ}$ alone. ${ }^{6}$ With dual therapy, we theorize that higher plasma concentrations of medication would have led to increased parasitic cell death and a greater therapeutic benefit. Garcia et al. (2014) however challenged this theory. In their study, they also used an additional high-dose $\mathrm{ABZ}$ treatment group. The results showed that although increasing the $\mathrm{ABZ}$ dose was more effective than the standard $A B Z$ regimen, it did not achieve the efficacy of combined ABZ plus PZQ. This suggests the additional cysticidal effect of $\mathrm{PZQ}$ is synergistic to $\mathrm{ABZ}$ and outperforms ABZ monotherapy alone. ${ }^{15}$

Current recommendations suggest considering dual therapy for parenchymal NCC when two or more viable cystic lesions are present on imaging. ${ }^{2,5}$ This follows the 2014 and 2016 studies published by Garcia et al. that found that combination therapy was superior to monotherapy for resolving symptoms and radiographic evidence of NCC only in patients with three or more viable parenchymal cysts. ${ }^{15,16}$ It seems that the synergistic effects of dual therapy pose a therapeutic advantage only with a certain threshold of cyst burden. Further research is warranted to establish why this is so.

Kaur et al. used only mono-cystic cases of NCC in children and concluded that combination therapy with $\mathrm{ABZ}+\mathrm{PZQ}$ is comparable to $\mathrm{ABZ}$ monotherapy in cyst resolution and seizure prevention. ${ }^{6} \mathrm{~A}$ consideration for future research would involve increasing the duration of dual therapy in mono-cystic NCC cases, as two treatment groups in Kaur et al. differed only by 1 day of Praziquantel $75 \mathrm{mg} / \mathrm{kg} .{ }^{6}$ This could determine whether $\mathrm{ABZ}+\mathrm{PZQ}$ therapy is therapeutically superior or equivalent to ABZ monotherapy in the treatment of NCC with a low cyst burden (i.e. patients with radiologic evidence of only one or two parenchymal cysts).

Multiple case reports and case series have proven the effectiveness of $A B Z+P Z Q$ in the treatment of NCC. Petrov et al. successfully treated NCC using a 14-day course of $\mathrm{ABZ}+\mathrm{PZQ}$ without any observed side effects. The patient had complete cysticerci eradication on imaging and full resolution of concomitant symptoms. ${ }^{19}$ Huang et al. treated 478 cases of NCC using PZQ (20 mg/kg per day) and ABZ (20 mg/kg per day) intermittently. One-year follow-up revealed an effective cure rate of $96.9 \%{ }^{20}$ Li et al. treated 1830 NCC patients with similar dosing and frequency as Huang et.al. and found that after three courses, $64.0 \%$ (1171) patients were cured. Of the remaining population, $25.1 \%$ (459) improved significantly, 9.1\% (167) improved and $1.8 \%$ (33) did not respond to treatment. Overall efficacy for Li's study was tabulated as $98.2 \% .^{21}$

Similarly, Wang et. al. treated 2539 cases of NCC with ABZ 20 $\mathrm{mg} / \mathrm{kg}$ daily for 12 days, followed by 12 days of PQZ $30 \mathrm{mg} / \mathrm{kg}$ daily. After an intermission of two to three months, the ABZ dose and frequency was repeated, followed by an increased dose of PQZ (50 mg/kg per day) for 15 days. The second regimen was repeated once or twice more after a paralleled period of interlude. After three to four courses of treatment, Wang e.t al. found $94.5 \%$ (1349/1427) of epileptic seizures were controlled. In 96.3\% (861/894) of the cases, symptoms such as headache, nausea, and vomiting subsided, and of those with memory impairment, $93.3 \%$ $(223 / 239)$ recovered completely. Imaging revealed complete cyst resolution in $82.9 \%$ cases, with only $17.1 \%$ (433/2539) of CT/ MRIs showing calcifications. ${ }^{22}$ These case reports and case series demonstrate the efficacy in $\mathrm{ABZ}+\mathrm{PZQ}$ dual therapy which was also seen in this systematic review.

Our systematic review has several limitations. Firstly, there are only a few studies with direct comparisons between combined $\mathrm{ABZ}+\mathrm{PZQ}$ and $\mathrm{ABZ}$ monotherapy in NCC. Between these studies, there are significant differences in patient characteristics, treatment regimen and presentation of results. We were thus unable to perform a meta-analysis to evaluate the effectiveness of combined regimen. Moreover, most of the included studies have a small sample size, making it difficult to extrapolate data.

Despite this, this study is, to the best of our knowledge, the first systematic review comparing the efficacy of combined $A B Z+P Z Q$ with $\mathrm{ABZ}$ monotherapy in the treatment of NCC. Our literature search was comprehensive and included publications across all languages. Additionally, our analysis includes a diverse patient population (Indian, South American, Chinese descent). It is essential that the evidence obtained from our study be applied on a large scale, across different populations worldwide, to reaffirm our findings.

\section{Conclusion}

$\mathrm{ABZ}+\mathrm{PZQ}$ dual therapy is more efficacious than $\mathrm{ABZ}$ monotherapy in the pharmacotherapeutic management of viable parenchymal multi-cystic NCC both in terms of symptom and radiographic lesion resolution. The side effect profile is similar in both groups. More studies with comparable brain lesions with similar treatment regimens are warranted.

\section{Abbreviations}

NCC: Neurocysticercosis

ABZ: Albendazole

PZQ: Praziquantel

ABZ+PZQ: Combined albendazole and praziquantel

CT: Computed tomography

MRI: Magnetic resonance imaging

PRISMA: Preferred Reporting Items for Systemic review and Meta-Analysis

CDC: Center of Disease Control

NPI: Neglected parasitic infections

\section{Declarations:}

\section{Acknowledgments}

None

\section{Authors' contributions}

GN, GSS, RSK and JHR designed the study. GN, RSK and JHR carried out literature search, review, and selection. GN, JHR, STA, BK, RS, JG and SJ analyzed the selected literatures and synthesized the results. GN, RS, STA, BK, YKS and JR drafted the manuscript. GN, YKS, JKY, RO, GSS and JHR were involved in revising the manuscript critically for important intellectual content. All authors read and approve the final manuscript.

\section{Funding}

We received no funds for conducting this study.

\section{Availability of data and materials}

No data sets were created in this study

Ethics approval and consent to participate

Not applicable for this kind of paper

\section{Consent for publication}

Not applicable.

\section{Competing interests}


None of the authors has any conflict of interest to disclose. We confirm that we have read the Journal's position on issues involved in ethical publication and affirm that this report is consistent with those guidelines.

\section{References}

1. WHO. Landscape analysis : management of neurocysticercosis with an emphasis on low- and middleincome countries. 2015. Available from: https://apps.who. int/iris/handle/10665/152896

2. Cantey P. Neurocysticercosis: Leading Cause of Acquired Epilepsy Worldwide. Medscape. 2016.

3. Coyle CM, Tanowitz HB. Diagnosis and Treatment ofNeurocysticercosis. Interdiscip Perspect Infect Dis. 2014;2009:180742.

4. Gripper LB, Welburn SC. Neurocysticercosis infection and disease-A review. Acta Trop [Internet]. 2017;166:21824. Available from: http://dx.doi.org/10.1016/j. actatropica.2016.11.015

5. White AC, Coyle CM, Rajshekhar V, Singh G, Hauser WA, Mohanty A, et al. Diagnosis and treatment of neurocysticercosis: 2017 clinical practice guidelines by the Infectious Diseases Society of America (IDSA) and the American Society of Tropical Medicine and Hygiene (ASTMH). Am J Trop Med Hyg. 2018;98(4):945-66.

6. Kaur S, Singhi P, Singhi S, Khandelwal N. Combination therapy with albendazole and praziquantel versus albendazole alone in children with seizures and single lesion neurocysticercosis: A randomized, placebo-controlled double blind trial. Pediatr Infect Dis J. 2009;28(5):403-6.

7. Garcia HH, Lescano AG, Lanchote VL, Pretell EJ, Gonzales I, Bustos JA, et al. Pharmacokinetics of combined treatment with praziquantel and albendazole in neurocysticercosis. $\mathrm{Br}$ J Clin Pharmacol. 2011;72(1):77-84.

8. Lima RM, Ferreira MAD, de Jesus Ponte Carvalho TM, Dumêt Fernandes BJ, Takayanagui OM, Garcia HH, et al. Albendazole-praziquantel interaction in healthy volunteers: Kinetic disposition, metabolism and enantioselectivity. Br J Clin Pharmacol. 2011;71(4):528-35.

9. Alvela-Suárez L, Velasco-Tirado V, Belhassen-Garcia M, Novo-Veleiro I, Pardo-Lledías J, Romero-Alegría A, et al. Safety of the combined use of praziquantel and albendazole in the treatment of human hydatid disease. Am J Trop Med Hyg. 2014;90(5):819-22.

10. Ayles HM, Corbett EL, Taylor I, Cowie AGA, Bligh J, Walmsley K, et al. A combined medical and surgical approach to hydatid disease: 12 years' experience at the Hospital for Tropical Diseases, London. Ann R Coll Surg Engl. 2002;84(2):100-5.

11. Taylor DH, Morris DL. Combination chemotherapy is more effective in postspillage prophylaxis for hydatid disease than either albendazole or praziquantel alone. $\mathrm{Br} \mathrm{J}$ Surg. 1989;76(9):954-954.

12. Olds GR, King C, Hewlett J, Olveda R, Wu G, Ouma J, et al. Double Blind Placebo Controlled Study of Concurrent Administration of Albendazole and Praziquantel in Schoolchildren with Schistosomiasis and Geohelminths. J Infect Dis. 1999;179(4):996-1003.

13. Guo D, Xie S, Jia J. Therapeutic efficacy of praziquantel, albendazole and a combination of the two drugs in cysticercosis. Zhongguo Ji Sheng Chong Xue Yu Ji Sheng Chong Bing Z Zhi. 2003;21:187-8.

14. Xu Hongxiu, Zhang Qingzhen, Liu Yulei, Mao Dehua, Shi Shijun XJ. Effect of praziquantel alone or albendazole alone or combination of two drugs in treatment of cysticercosis. J Qiqihar Med Coll. 2001;22(9):999-1000. Available from: http://caod.oriprobe.com/articles/4042765/zuo_zuo_ tong_ji_a_ben_da_zuo_dan_yong_huo_lian_yong_kang_ nang_wei_zuo_.htm?fbclid=IwAR3 tw8pOmP5 zmEFwkincySUzwe3yXcOvJ4g80nDQAi9r4qT14ksAEdE4_6w

15. Garcia HH, Gonzales I, Lescano AG, Bustos JA, Zimic M, Escalante D, et al. Efficacy of combined antiparasitic therapy with praziquantel and albendazole for neurocysticercosis: A double-blind, randomised controlled trial. Lancet Infect Dis [Internet]. 2014;14(8):687-95. Available from: http://dx.doi.org/10.1016/S1473-3099(14)70779-0

16. Garcia HH, Lescano AG, Gonzales I, Bustos JA, Pretell EJ, Horton J, et al. Cysticidal efficacy of combined treatment with praziquantel and albendazole for parenchymal brain cysticercosis. Clin Infect Dis. 2016;62(11):1375-9.

17. Liberati A, Altman DG, Tetzlaff J, Mulrow C, Gøtzsche PC, Ioannidis JPA, et al. The PRISMA statement for reporting systematic reviews and meta-analyses of studies that evaluate health care interventions: explanation and elaboration. J Clin Epidemiol. 2009;62(10):e1-34.

18. Ma Yunxiang, Xue Xiaoling YQ. Suggestions on diagnosis, clinical typing and criteria of therapeutic efficacy in cerebral cysticercosis. Chinese J Parasitol Parasit Dis. 1989;7(2):134-5.

19. Petrov K, Ihongbe F, Chang M, Choudhary S, Bhatia D. Combined Albendazole and Praziquantel Therapy in an Adult Female with Neurocysticercosis and Generalized Tonic-clonic Seizures. Cureus. 2018;10(7):4-6.

20. Huang MH, Li QC PP. Clinical effect of the combination of praziquantel and albendazole on brain cysticercosis: a report of 478 cases. J Dali Med Colg. 2001;10:32-3.

21. Li QinCui , Huang MingHao, Yang YaNan LW. Clinical analysis of 1830 acute cases of cerebral cysticercosis. J Pathog Biol. 2011;6(12):924-5.

22. Wang ZL, Kou JX, Hu YX, Liu YL, Mao DH CH. Clinical observation on the effect of combined use of praziquantel and albendazole on cerebral cysticercosis. China Trop Med [Internet]. 2008;8(11):1873-6. Available from: http:// zgrdyx.periodicals.net.cn/default.html https://www.cabdirect.org/cabdirect/abstract/20093030274 
The efficacy of combined Albendazole and Praziquantel therapy versus Albendazole monotherapy in treatment of parenchymal neurocysticercosis: A systematic review
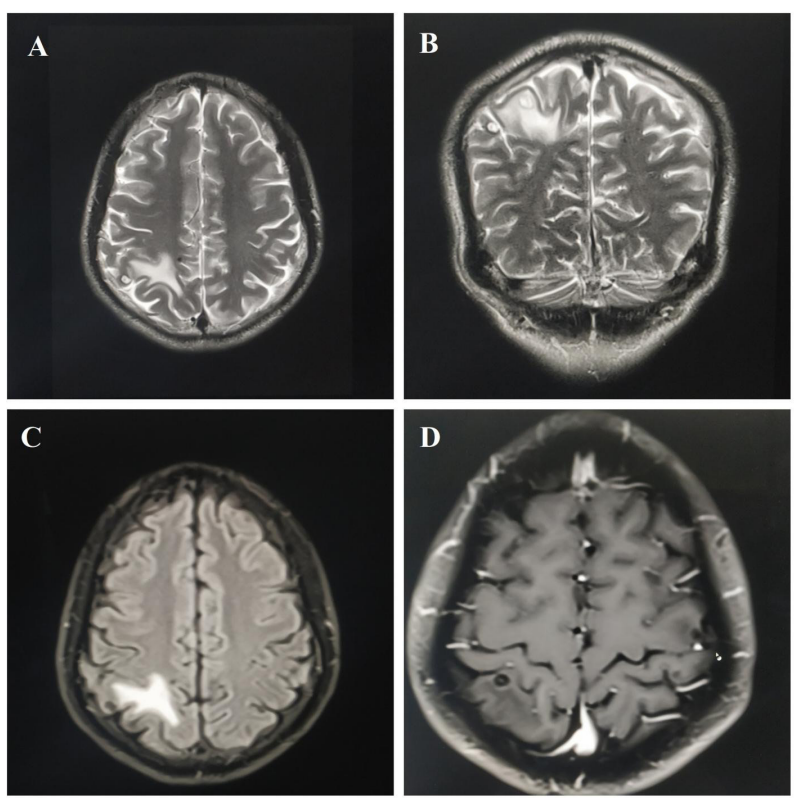

Figure 1: Magnetic resonance imaging (MRI) of a 22 years old male who presented with generalized tonic-clonic seizure. Various MRI sequences and contrast study suggested for Neurocysticercosis.

A: $\quad$ MRI brain T2-weighted axial image showing a lesion with a hyperintense cystic wall with central low signal intensity in the right parietal lobe. There is a T2 high signal intensity area surrounding the lesion, suggestive of perilesional edema.

B: MRI brain T2-weighted coronal image showing two lesions with a hyperintense cystic wall with central low signal intensity in the right parietal lobe. There is a T2 high signal intensity area adjacent to the lesions, suggestive of perilesional edema.

C: MRI brain FLAIR axial image showing low signal intensity lesion with surrounding high signal intensity in the right parietal lobe suggestive of a cyst with perilesional edema.

D: Post-gadolinium T1-weighted axial MRI brain showing a ring-enhancing lesion containing a hyperintense dot in the right parietal lobe.

Figure 2: PRISMA flow diagram displaying the results of our

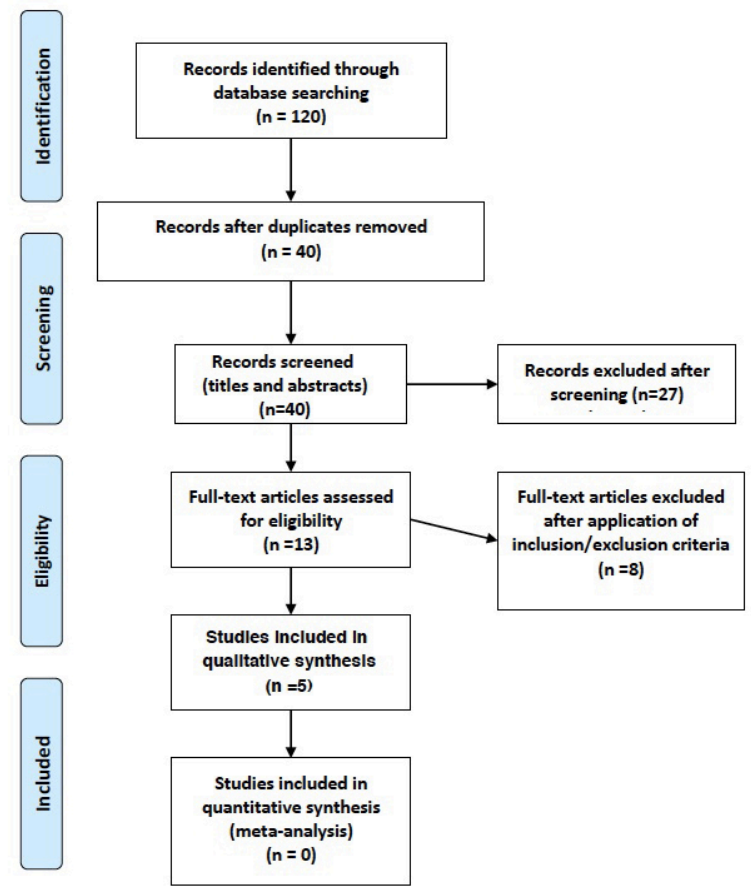

literature search and selection

Table 1: Key methodological characteristics of included studies.

\begin{tabular}{|c|c|c|c|c|c|c|c|c|}
\hline \multirow[t]{2}{*}{$\begin{array}{l}\text { Au- } \\
\text { thor }\end{array}$} & \multirow[t]{2}{*}{ Year } & \multirow[t]{2}{*}{$\begin{array}{c}\text { Coun- } \\
\text { try }\end{array}$} & \multirow[t]{2}{*}{$\begin{array}{l}\text { Study } \\
\text { design }\end{array}$} & \multicolumn{2}{|c|}{$\begin{array}{c}\text { Treatment } \\
\text { groups: } \mathbf{n}(\%)\end{array}$} & \multicolumn{2}{|c|}{ Drug doses } & \multirow[t]{2}{*}{$\begin{array}{c}\text { Concomitant } \\
\text { therapy }\end{array}$} \\
\hline & & & & $\begin{array}{c}\mathrm{AL}- \\
\mathrm{B}+\mathrm{PZQ}\end{array}$ & ALB & $\mathrm{ALB}+\mathrm{PZQ}$ & ALB & \\
\hline $\begin{array}{c}\text { Xu et } \\
\mathrm{al}^{14}\end{array}$ & 2001 & China & $\begin{array}{l}\text { Non-ran- } \\
\text { domized } \\
\text { trial }\end{array}$ & 40 & 631 & $\begin{array}{l}\text { ALB } 20 \mathrm{mg} / \mathrm{kg} \text { daily for } \\
12 \text { days, following } \\
\text { PZQ } 30 \mathrm{mg} / \mathrm{kg} \text { daily for } \\
12 \text { days as a course and } \\
\text { with two courses, the } \\
\text { intermittence was } 2 \text { to } 3 \\
\text { months }\end{array}$ & $\begin{array}{l}15 \mathrm{mg} / \mathrm{kg} \text { daily for } 15 \\
\text { days as a course and } \\
\text { with two courses, and } \\
\text { the intermittence was } \\
2 \text { to } \\
3 \text { months }\end{array}$ & Not mentioned \\
\hline $\begin{array}{l}\text { Guo } \\
\text { et al }{ }^{13}\end{array}$ & 2003 & China & $\begin{array}{l}\text { Non-ran- } \\
\text { domized } \\
\text { trial }\end{array}$ & 30 & 30 & $\begin{array}{l}\text { The total dosages of } \\
\text { ALB and PZQ were } 100 \\
\mathrm{mg} / \mathrm{kg} \text {, respectively. } \\
\text { Course of treatment was } \\
2 \text { to } 4 \text { weeks. }\end{array}$ & $\begin{array}{l}200 \mathrm{mg} / \mathrm{kg} \text { total dose. } \\
\text { Course of treatment } \\
\text { was } 2 \text { to } 4 \text { weeks }\end{array}$ & $\begin{array}{l}\text { Anti-epileptics, } \\
\text { Antibiotics, } \\
\text { Drugs to lower in- } \\
\text { tracranial pressure }\end{array}$ \\
\hline
\end{tabular}




\begin{tabular}{|c|c|c|c|c|c|c|c|c|}
\hline $\begin{array}{l}\text { Kaur } \\
\text { et } \mathrm{al}^{6}\end{array}$ & 2009 & India & RCT & 53 & 50 & $\begin{array}{l}\text { ALB } 15 \mathrm{mg} / \mathrm{kg} / \text { day for } \\
7 \text { days and PZQ } \\
75 \mathrm{mg} / \mathrm{kg} / \text { day for } 1 \text { day }\end{array}$ & $\begin{array}{l}15 \mathrm{mg} / \mathrm{kg} / \text { day for } 7 \\
\text { days }\end{array}$ & $\begin{array}{l}\text { Oral prednisolone } \\
(2 \mathrm{mg} / \mathrm{kg} / \mathrm{d}) \text { for the } \\
\text { initial } 5 \text { days. } \\
\text { Carbamazepine } 12 \text { to } \\
15 \mathrm{mg} / \mathrm{kg} / \text { day }\end{array}$ \\
\hline $\begin{array}{l}\text { Gar- } \\
\text { cia et } \\
\mathrm{al}^{15}\end{array}$ & 2014 & Peru & RCT & 39 & 41 & $\begin{array}{l}10 \text { days of combined } \\
\text { ALB (15 mg/kg per day) } \\
\text { plus PZQ } \\
(50 \mathrm{mg} / \mathrm{kg} \text { per day) }\end{array}$ & $\begin{array}{l}15 \mathrm{mg} / \mathrm{kg} \text { per day for } \\
10 \text { days }\end{array}$ & $\begin{array}{l}\text { Phenytoin or carba- } \\
\text { mazepine, dexameth- } \\
\text { asone at } 0.1 \mathrm{mg} / \mathrm{k} / \mathrm{d} \text {, } \\
\text { divided into } 2 \text { doses } \\
\text { (morning and eve- } \\
\text { ning), and } \\
300 \mathrm{mg} / \mathrm{d} \text { of ranit- } \\
\text { idine }\end{array}$ \\
\hline $\begin{array}{l}\text { Gar- } \\
\text { cia et } \\
\text { al }^{16}\end{array}$ & 2016 & Peru & RCT & 16 & 16 & $\begin{array}{l}\mathrm{PZQ} \text { at } 50 \mathrm{mg} / \mathrm{k} / \mathrm{day} \\
\text { and } \mathrm{ABZ} 15 \mathrm{mg} / \mathrm{k} / \mathrm{d} \text {, } \\
\text { both for } 9 \text { and half days }\end{array}$ & $\begin{array}{l}\mathrm{ABZ} 15 \mathrm{mg} / \mathrm{k} / \text { day for } 9 \\
\text { and half days }\end{array}$ & $\begin{array}{l}\text { Phenytoin or carba- } \\
\text { mazepine, dexameth- } \\
\text { asone at } 0.1 \mathrm{mg} / \mathrm{k} / \mathrm{d} \text {, } \\
\text { divided into } 2 \text { doses } \\
\text { (morning and eve- } \\
\text { ning), and } \\
300 \mathrm{mg} / \mathrm{d} \text { of ranit- } \\
\text { idine }\end{array}$ \\
\hline
\end{tabular}

PZQ: Praziquantel; ALB: Albendazole

Table 2: Characteristics of patients included in selected studies.

\begin{tabular}{|c|c|c|c|c|c|c|c|}
\hline \multirow{2}{*}{ Author } & \multirow{2}{*}{ Year } & \multicolumn{2}{|c|}{ Age $($ Mean \pm SD) } & \multicolumn{2}{|c|}{ Male to female ratio } & \multicolumn{2}{|c|}{$\begin{array}{l}\text { Number of cysts at baseline } \\
\qquad(\text { Mean } \pm \text { SD) }\end{array}$} \\
\hline & & $\mathrm{ALB}+\mathrm{PZQ}$ & ALB & $\mathrm{ALB}+\mathrm{PZQ}$ & ALB & $\mathrm{ALB}+\mathrm{PZQ}$ & ALB \\
\hline $\mathrm{Xu}$ et $\mathrm{al}^{14}$ & 2001 & \multicolumn{2}{|c|}{$35.89 \pm 16$} & \multicolumn{2}{|c|}{1.6} & \multicolumn{2}{|c|}{ Not available } \\
\hline Guo et $\mathrm{al}^{13}$ & 2003 & $36.8 \pm 11.4$ & $37.5 \pm 10.9$ & 2 & 1.5 & $10.1 \pm 4.9$ & $9.1 \pm 5.4$ \\
\hline Kaur et $\mathrm{a}^{16}$ & 2009 & $7.2 \pm 0.76$ & $7.3 \pm 0.84$ & 1.9 & 1.3 & $\begin{array}{l}1 \text { (Single } \\
\text { lesion) }\end{array}$ & $\begin{array}{l}1 \text { (Single } \\
\text { lesion) }\end{array}$ \\
\hline Garcia et $\mathrm{al}^{15}$ & 2014 & $34 \pm 14$ & $35 \pm 13$ & 1.73 & 2 & $5 \pm 5$ & $4 \pm 4$ \\
\hline Garcia et $\mathrm{al}^{16}$ & 2016 & $29.3 \pm 9.7$ & $27.5 \pm 11.0$ & 1.45 & 1.6 & $5.13 \pm 5.43$ & $4.81 \pm 3.51$ \\
\hline
\end{tabular}

PZQ: Praziquantel; ALB: Albendazole 